\title{
Spatial and temporal variations of channel lateral migration rates in the Inner Mongolian reach of the upper Yellow River
}

\author{
Suiji Wang ${ }^{1} \cdot \operatorname{Ling} \mathrm{Li}^{1} \cdot$ Lishan $\operatorname{Ran}^{2} \cdot$ Yunxia $\operatorname{Yan}^{1}$
}

Received: 6 December 2015/ Accepted: 7 September 2016/Published online: 14 September 2016

(C) Springer-Verlag Berlin Heidelberg 2016

\begin{abstract}
Channel variations of the Inner Mongolian reach in the upper Yellow River are very complicated because of diversity of channel patterns, intense changes in water and sediment, and enhanced human activities in the last decades. It is important to examine the channel migration rates in this river reach. Based on channel planform changes at 236 digital channel cross-sections, the present study estimated the channel migration rates in terms of mid-channel line shift at the digital channel cross-sections during the periods 1975-1990, 1990-2000, 2000-2006, 2006-2010, and 2010-2011. The results show that the average channel migration rate for the whole river reach is 5.0, 7.9, -5.9, 8.6 , and $-1.0 \mathrm{~m}^{-1}$ in the five different periods, respectively. In both directions to the right and to the left, the highest channel migration rate was always observed in the meandering channels, while the lowest channel migration rate was in the whole Inner Mongolian reach except the Sanhuhekou-Zhaojunfen (S-Z) sub-reach. The temporal variation of channel migration rate was mainly controlled by changing sediment concentration in river flow, while the spatial variation along the straight, braided, and meandering channel reaches was largely affected by material differences of channel banks as reflected by different channel patterns. With the highest average lateral migration rate to the left bank, the meandering channel reach is extremely
\end{abstract}

Suiji Wang

wangsj@igsnrr.ac.cn

1 Key Laboratory of Water Cycle and Related Land Surface Processes, Institute of Geographic Sciences and Natural Resources Research, Chinese Academy of Sciences, Beijing 100101, China

2 Department of Geography, The University of Hong Kong, Pokfulam Road, Hong Kong, China vulnerable to lateral migration and needs to be protected with engineering practices, because a large population and wide farmland are located on its left floodplain.

Keywords River channel · Migration rate · Variations · Channel pattern · Inner Mongolian reach · Yellow River

\section{Introduction}

The Yellow River is geomorphologically one of the largest and most active rivers in the world, with a total alluvial channel length of $>2000 \mathrm{~km}$ and a total channel length of $5464 \mathrm{~km}$. Three different channel patterns, namely braided, meandering, and straight, developed downstream in the alluvial reaches of the lower Yellow River (Wang and $\mathrm{Li}$ 2011). However, this channel pattern diversity also appeared in the alluvial Inner Mongolian reach of the upper Yellow River. Development of different channel patterns is mostly the result of natural processes (Twidale 2004). A river channel becomes braided when the supply of sediment load exceeds the sediment-carrying capacity of the flow, resulting in an aggrading channel bed characterized by a series of mid-channel sandbars (Alam et al. 2007; Baki and Gan 2012). Alternatively, it develops toward meandering when the sediment supply equals approximately the sediment-carrying capacity of the flow. River channel changes, such as downcutting and aggradation in channel bed (e.g., Moshe et al. 2008; Zahar et al. 2008), erosion and accretion at channel banks (e.g., Takagi et al. 2007; Kummu et al. 2008; Baki and Gan 2012), and transformations of channel patterns (Wang and Li 2011), are natural processes for an alluvial river (e.g., Kummu et al. 2008; Wang et al. 2014). Numerous studies have indicated that channel change for different rivers, or for 
different river patterns in a river, can be induced by diverse driving factors. For instance, frequent large floods have triggered significant changes in the braided Brahmaputra River, Bangladesh (Takagi et al. 2007), while for the Rio Grande River in New Mexico of USA, the accelerated lateral channel migration was primarily caused by increased flow energy (Richard et al. 2005). Furthermore, valley confinement has played a critical role in controlling the evolution of the braided Platte River (Fotherby 2009). However, human activities, such as construction of artificial levees and dams, operation of reservoirs and barrages, and building of bank protection structures on river banks, have played increasingly more important roles in channel evolution by modifying natural geomorphologic dynamics of river systems at least in the past decades (e.g., Petts 1979, 1984; Church 1995; Brandt 2000; Ran et al. 2010; Wang and Li 2011; Hossain et al. 2013). In such alluvial rivers, the channels change frequently from reach to reach as a result of continuous erosion-accretion processes (Kummu et al. 2008). Consequently, these changes can cause a variety of socioeconomic and environmental problems in loss of riparian land and infrastructure, bank stability and flood disasters (e.g., Takagi et al. 2007; Belletti et al. 2015), and the alteration of aquatic and riparian ecosystems. Therefore, a better understanding on river channel changes, lateral migration in particular, is urgently needed. Detecting such changes is of great importance for effective planning and environmental management (Kummu et al. 2008; Hossain et al. 2013).

As a typical alluvial river reach in the upper Yellow River, the Inner Mongolian reach is characterized by frequent channel shifts and evident morphological changes caused by a low channel gradient and loose material composed mainly of silts and fine sands in riverbed and banks (Hou et al. 2007). Thus, the Inner Mongolian river reach has attracted increasingly more attention because of its complexity in channel evolution, sediment transport, and intensive human influences. A number of studies have focused on those problems, and convincing results have been obtained. By estimating the changes in erosion area of the river banks in the river reach based on satellite images, Yao et al. (2011) found that the annual mean erosion area presented a decreasing trend since the 1960s. Wang et al. (2012) further studied the spatiotemporal variations of suspended sediment filling capacity and sedimentation rate in the river reach and concluded that a deposition-erosiondeposition pattern occurred in the middle and lower reaches during the periods 1952-1959, 1960-1985, and 1986-2007, while sediment deposition dominated in the upper reach throughout all the periods. Recent studies have also paid attention to channel morphological changes by analyzing responses of channel cross-sections to flood processes (Wang and Fan 2010) and by investigating channel hydraulic geometry characteristics (Ran et al. 2012). Moreover, natural and anthropogenic impacts on the channel changes have also been broadly discussed (e.g., Hou et al. 2007; Shen et al. 2007; Ran et al. 2010; Wang et al. 2012). In contrast, little work has been done regarding the channel migration rate for the Inner Mongolian reach. Particularly, a critical problem is how to quantify the channel migration rates of a fluvial river characterized by inadequate channel geometry data (Petts 1995; Wang et al. 2014).

The purposes of this paper are to (1) draw the channel planforms and mid-channel lines for the Inner Mongolian reach of the upper Yellow River in the years of 1975, 1990, 2000, 2006, 2010, and 2011; (2) obtain the location data of the intersection points between fixed 236 digital crosssections and the mid-channel lines in the studied years; (3) calculate channel migration rates at each cross-section and channel mean migration rates for each sub-reaches and for the whole river reach, based on location changes in the intersection points during the periods 1975-1990, 1990-2000, 2000-2006, 2006-2010, and 2010-2011; and (4) compare the spatial and temporal variations of the channel migration rates and analyze their dominant impacts. The results are of great significance for understanding the channel evolution and for river management in the river reach.

\section{Materials and methods}

\section{Study area}

The study reach is located between Shizuishan and Toudaoguai (Fig. 1), commonly called the Inner Mongolian reach of the upper Yellow River, and has a total channel length of $715 \mathrm{~km}$ and a mean channel gradient of $1.59 \times 10^{-4}$ (Wang and Fan 2010). Five major gauging stations, including Shizuishan, Bayangaole, Sanhuhekou, Zhaojunfen, and Toudaoguai, were established along the river reach since the 1950s (Fig. 1). Those stations divide the river reach into four sub-reaches with a channel length of 151, 236, 138, and $190 \mathrm{~km}$, respectively. From Shizuishan to Bayangaole (S-B), the river flows northward along the eastern margin of the Wulanbuhe Desert, with an elevation difference of $35 \mathrm{~m}$ and a mean channel gradient of $2.3 \times 10^{-4}$. It mainly presents a straight channel pattern in the river sub-reach, and outcrop of bedrock can be observed in the upper section (with a channel long of $25 \mathrm{~km}$ ) of the sub-reach. The channel width ranges from 300 to $700 \mathrm{~m}$. In the downstream reach from Bayangaole to Sanhuhekou (B-S), Sanhuhekou to Zhaojunfen (S-Z), and Zhaojunfen to Toudaoguai (Z-T), the river flows eastward and traverses the southern margin of the Hetao Plain, with 


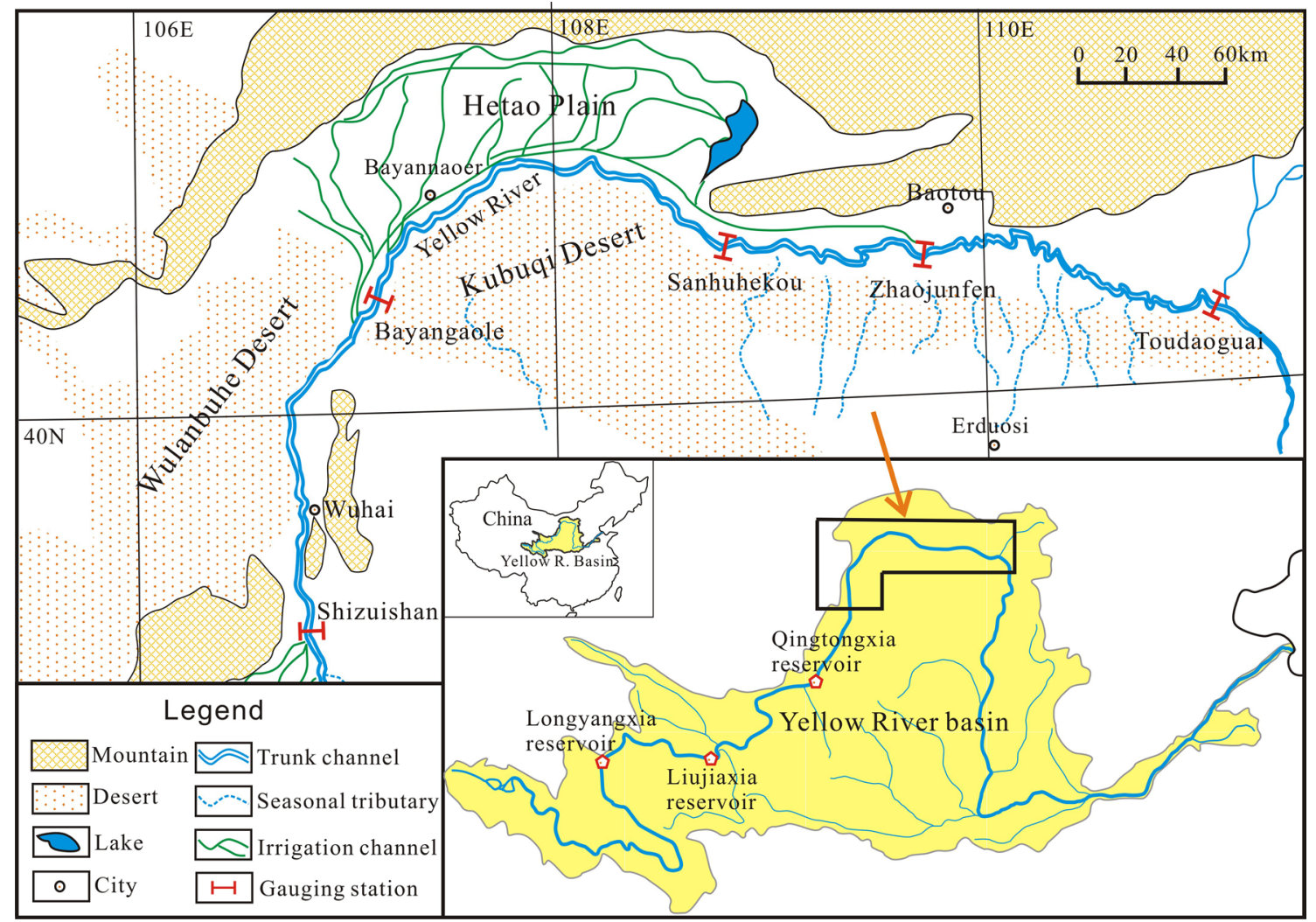

Fig. 1 Location of the channel reach from Shizuishan to Toudaoguai gauging stations and the major gauging stations in the study area

a channel gradient of $1.23 \times 10^{-4}, 1.09 \times 10^{-4}$, and $1.04 \times 10^{-4}$, respectively. The river channel exhibits braided (in B-S sub-reach) and meandering (in S-Z and Z$\mathrm{T}$ sub-reaches) patterns, respectively (Wang et al. 2012). The total elevation difference of the channel bed is $63 \mathrm{~m}$ and the average channel gradient is $1.1 \times 10^{-4}$ for the three sub-reaches together. The channel width in the three sub-reaches ranges from 500 to $2500 \mathrm{~m}$. In addition, the population in Bayannaoer and Baotou (Fig. 1) is 4.5 million, and the total farmland area in Hetao Plain is $44,000 \mathrm{~km}^{2}$. The Hetao Plain is located in the left side of the river reach from Bayangaole to Toudaoguai stations.

The drainage basin in this river reach is situated in a dry climate with a mean annual precipitation of $200-250 \mathrm{~mm}$ and evapotranspiration of 1000-2000 mm (Yellow River Conservancy Commission 1989). Several small ephemeral tributaries with small water discharge and sediment load flow into the main channel. The mean annual runoff at Shizuishan station, the input control station of the river reach, is $273.21 \times 10^{8} \mathrm{~m}^{3}$ year $^{-1}$, while the mean annual suspended sediment load (SSL) is $1.24 \times 10^{8} \mathrm{t} \mathrm{year}^{-1}$ during the period 1952-2007 (Wang et al. 2012). The mean annual sediment concentration (SC) is $4.54 \mathrm{~kg} \mathrm{~m}^{-3}$, while $5.16 \mathrm{~kg} \mathrm{~m}^{-3}$ in the flooding season from May to October over the same period. Several large reservoirs, such as the
Qingtongxia, Liujiaxia, and Longyangxia reservoirs, are located above the Shizuishan station (Fig. 1). They were constructed in 1968, 1968, and 1986, respectively, and are 199, 783, and $1117 \mathrm{~km}$, respectively, upstream of the Shizuishan station. Since the operation of these reservoirs, both water flow and sediment delivery below the reservoirs, especially in the Inner Mongolian channel reach, have been significantly affected. Reservoir operation in combination with other anthropogenic impacts, such as water withdrawal for irrigation and domestic and industrial consumptions in the Hetao Plain, and climate change have resulted in dramatic reductions in annual runoff and suspended sediment load (SSL). For example, the annual runoff and SSL at Shizuishan station have decreased by 18.6 and $55.4 \%$ from $313.95 \times 10^{8} \mathrm{~m}^{3}$ year $^{-1}$ and $2.02 \times 10^{8} \mathrm{t} \mathrm{year}^{-1}$ in the period 1952-1968 to $255.46 \times 10^{8} \mathrm{~m}^{3}$ year $^{-1}$ and $0.90 \times 10^{8} \mathrm{t} \mathrm{year}^{-1}$ in the period 1969-2007, respectively.

\section{Data}

The data used in this study include satellite images in the years of 1975, 1990, 2000, 2006, 2010, and 2011 and annual runoff at Sanhuhekou gauging station during the period 1952-2011. The adopted satellite images captured 
in the flooding season from June to September were downloaded from http://earthexplorer.usgs.gov/ (data available from the U.S. Geological Survey). The resolution of the images is $30 \mathrm{~m}$ in 1990, 2006, 2010, and 2011, while 80 and $15 \mathrm{~m}$ in 1975 and 2000, respectively (Table 1). With these images, the boundary of the channel was first digitalized, and the mid-channel line was then delineated, upon which the channel planform in the different years was determined. The annual runoff and SSL during the period 1952-2011 at Sanhuhekou gauging station were used to show the variation trend of the hydrological data. These hydrological data were measured by the Yellow River Water Conservancy Commission and documented in the 'Hydrological Yearbook of the Yellow River' (Yellow River Water Conservancy Committee 1952).

\section{Methods}

Hydrological gauging stations are very rare in the Inner Mongolian reach of the Yellow River. Only five stations were established with a mean interval of $179 \mathrm{~km}$. Thus, it is difficult to survey the planform changes for the river reach based only on those gauging stations because the channel change characteristics between these stations are not clear. As an important and powerful tool to obtain channel planform changes, satellite images have been widely applied in fluvial geomorphology studies (Khan and Islam 2003; Kummu et al. 2008; Yao et al. 2011; Baki and Gan 2012; Hossain et al. 2013; Wang et al. 2014). Generally, channel boundary could be easily delineated by using stream water boundary because this boundary is highly detectable from satellite images, if the river flow width does not change apparently with water level (Nicoll and Hickin 2010). However, if satellite images were taken in flooding season in a year and in non-flooding season in another year, the water boundary is not a perfect indicator to show the channel migration of broad and shallow channels, such as braided rivers. In this studied river reach, the upper section of the Bayangaole-Sanhuhekou sub- reach presents a typical braided river pattern. Although the limit of vegetation could be an important indicator of channel boundary (e.g., Gurnell 1997; Winterbottom 2000; Richard et al. 2005; Yao et al. 2013; Wang et al. 2014), it is seldom distributed in the study river reach, in particular along the margins of the Wulanbuhe and Kubuqi deserts.

To eliminate the influences of obvious river-level changes between flooding and non-flooding seasons, we used only the water boundary of the satellite images obtained in flooding season for the years to digitize the channel boundary. As Wang et al. (2014) noted, the precision of the delineated channel boundary is primarily dependent on image resolution. This indicates that satellite images will mainly affect the drawing accuracy for the banks, and would not significantly influence the channel width far from a resolution distance between the banks. Therefore, the possible maximum absolute error in digitizing the channel boundary is a pixel (i.e., resolution of the images), while it is twice the pixel in calculating the baseline length of the cross-sections between the channel banks. For the mid-channel line calculated from the digitized channel boundary, the possible maximum absolute errors will also be one pixel. Considering the lower possible errors, the migration rate of the mid-channel line is designated as the channel migration rate. The mean possible maximum relative errors for the mid-channel line calculation are listed in Table 1.

Comparing the fixed close digital cross-sections from multi-temporal satellite images provides a convenient way to calculate the channel migration rate (Wang et al. 2014). The interval of the digital cross-sections can be easily selected depending on the requirements of a given study. In this study, the channel perpendicular fixed digital crosssections in the images taken in 1975 (Fig. 2). If adopted parallel across-sections in this river reach, some crosssections could change along the channel with channel evolution over a long time period. But adopted channel perpendicular cross-sections in the images of 1975 can keep the cross-sections across the channel with channel

Table 1 Date of the obtained remote sensing images, average channel width, and possible maximum relative error when digitizing the midchannel line in different years

\begin{tabular}{lllllllll}
\hline Year & Dates & $\begin{array}{l}\text { Image } \\
\text { types }\end{array}$ & $\begin{array}{l}\text { Image } \\
\text { resolution } \\
(\mathrm{m})\end{array}$ & $\begin{array}{l}\text { Maximum } \\
\text { discharge } \\
\left(\mathrm{m}^{3} / \mathrm{s}\right)\end{array}$ & $\begin{array}{l}\text { Mean } \\
\text { discharge } \\
\left(\mathrm{m}^{3} / \mathrm{s}\right)\end{array}$ & $\begin{array}{l}\text { Channel } \\
\text { length }(\mathrm{km})\end{array}$ & $\begin{array}{l}\text { Average channel } \\
\text { width (m) }\end{array}$ & $\begin{array}{l}\text { Maximum } \\
\text { relative error }(\%)\end{array}$ \\
\hline 1975 & June 17-September 14 & MSS & 80 & 2700 & 1608.9 & 675.1 & 1205 & 6.6 \\
1990 & July 8-August 27 & TM & 30 & 1670 & 802.5 & 670.1 & 995 & 3.0 \\
2000 & June 11-July 25 & ETM & 15 & 1310 & 634.8 & 726.9 & 335 & 4.5 \\
2006 & July 31-September 26 & TM & 30 & 1660 & 806.9 & 718.2 & 506 & 5.9 \\
2010 & July 1-September 5 & TM & 30 & 1700 & 650.9 & 706.6 & 514 & 5.8 \\
2011 & June 6-August 7 & TM & 30 & 788 & 435.5 & 745.8 & 475 & 6.3 \\
\hline
\end{tabular}

The discharge in 2000 was gauged at Toudaoguai station, while others at Sanhuhekou station 
evolution furthest. In total, 236 digital cross-sections with a mean interval of $\sim 3.0 \mathrm{~km}$ were delineated (Fig. 3). Considering the great differences in channel change in the meander belt of the meandering channel reach, denser digital cross-sections were detected. For example, the interval of the digital cross-sections in the channel subreaches of Bayangaole-Zhaojunfen (B-Z) and ZhaojunfenToudaoguai (Z-T) is 2.34 and $2.75 \mathrm{~km}$, respectively. These cross-sections are vectors and their locations are fixed in different year's images. The WGS84 coordinates were adopted to digitize channel boundary and to calculate channel change. The satellite images adopted were first calibrated based on a relief map with a scale of 1:50,000. To highlight river boundary and main flow features, the false color synthesis in the MSS data was used with the bands of 7, 4, and 2, while for the TM and ETM data the bands of 4, 3, and 2 were used for false color synthesis. ArcGIS 9.3 software was used to digitize the vector channel planforms and the vector mid-channel lines. Furthermore, the FME software (Feature Manipulate Engineering, a software developed by Safe Software Corporation in Canada) was used to select the intersection points of the cross-sections with the mid-channel lines. The obtained intersection points were taken as the base data for calculating the channel migration rates. The migration rate of an intersection point during a period can be calculated as follows:

$r=\sqrt{\left(x_{2}-x_{1}\right)^{2}+\left(y_{2}-y_{1}\right)^{2}} / Y$

where $r\left(\mathrm{~m} \mathrm{year}^{-1}\right)$ is the migration rate of an intersection point between mid-channel line and a digital cross-section from points a $\left(x_{1}, y_{1}\right)$ to $\mathrm{b}\left(x_{2}, y_{2}\right)$ (Fig. 2). In this study, the migration rates were regarded as positive when the intersection points migrated to the right, while as negative when

\section{Cross sections}

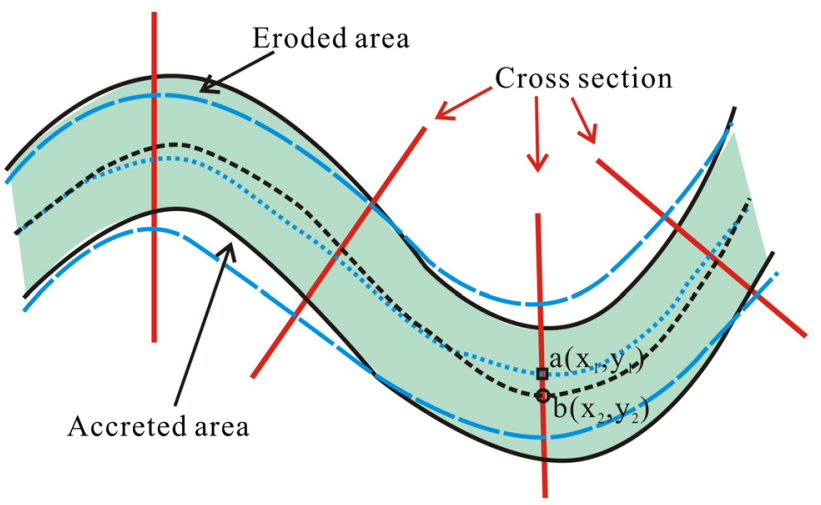

$\mathrm{a}\left(\mathrm{x}_{1}, \mathrm{y}_{1}\right)$ and $\mathrm{b}\left(\mathrm{x}_{2}, \mathrm{y}_{2}\right)$ are the points of intersection between mid-channel line and a cross-section in first and second year, respectively

Fig. 2 Diagram of the arrangement patterns of cross-sections the intersection points migrated to the left during a certain period. $Y$ is the years during the period.

For a given river reach, the channel shifts commonly show two different directions along the river reach: to the left in a short channel section or to the right in the adjacent short channel section (Wang et al. 2014). The mean channel migration distance in a river reach could be defined as the net mean shift distance to one direction, rightward or leftward. The mean channel migration rate in a channel sub-reach or in the whole river reach during a period was calculated as follows:

$$
\begin{aligned}
R= & \sum_{1}^{n}\left(a_{1}+a_{2}+\cdots+a_{n}\right) /(n+m)-\sum_{1}^{m}\left(\left|b_{1}\right|+\left|b_{2}\right|\right. \\
& \left.+\cdots+\left|b_{m}\right|\right) /(n+m)
\end{aligned}
$$

where $R$ (m year ${ }^{-1}$ ) is the mean channel migration rate; $a$ ( year $^{-1}$, positive) is rightward migration rate for a intersection point between the mid-channel line and a digital cross-section; $n$ is the number of the rightward migrated intersection points; $b$ (m year ${ }^{-1}$, negative) is leftward migration rate for a intersection point between the mid-channel line and a digital cross-section; $m$ is the number of the leftward migrated intersection points; $(n+m)$ is the total number of the digital cross-sections in a river reach. It indicates the channel migration to the right if $R$ is a positive, while to the left if $R$ is negative.

To compare the spatial changes in channel lateral migration, the river reach was divided into four subreaches, including Shizuishan-Bayangaole (S-B), Bayangaole-Sanhuhekou (B-S), Sanhuhekou-Zhaojunfen (S-Z), and Zhaojunfen-Toudaoguai $(\mathrm{Z}-\mathrm{T})$, based on the environment complexity and the geographic locations of the five gauging stations as well as the predominant channel patterns.

\section{Results}

Changes in channel planform of the four channel subreaches in the years of 1975, 1990, 2000, 2006, 2010, and 2011 are presented in Figs. 4a, 5a, 6a, and 7a, respectively. Based on these planform changes, the spatial variations of channel migration rates along the channel sub-reaches during the five time intervals of 1975-1990, 1990-2000, 2000-2006, 2006-2010, and 2010-2011 are shown in Figs. 4b, 5b, 6b, and 7b, respectively. The mean channel migration rates for both migration directions (to the left and to the right) in different channel sub-reaches and the average channel migration rates for different subreaches and that for the whole river reach in the five periods are listed in Table 2. 
Fig. 3 Locations of the 236 cross sections in the study area and the four channel subreaches, $S-B$ from Shizuishan to Bayangaole, $B-S$ from Bayangaole to Sanhuhekou, $S-Z$ from Sanhuhekou to Zhaojunfen, $Z-T$ from Zhaojunfen to Toudaoguai

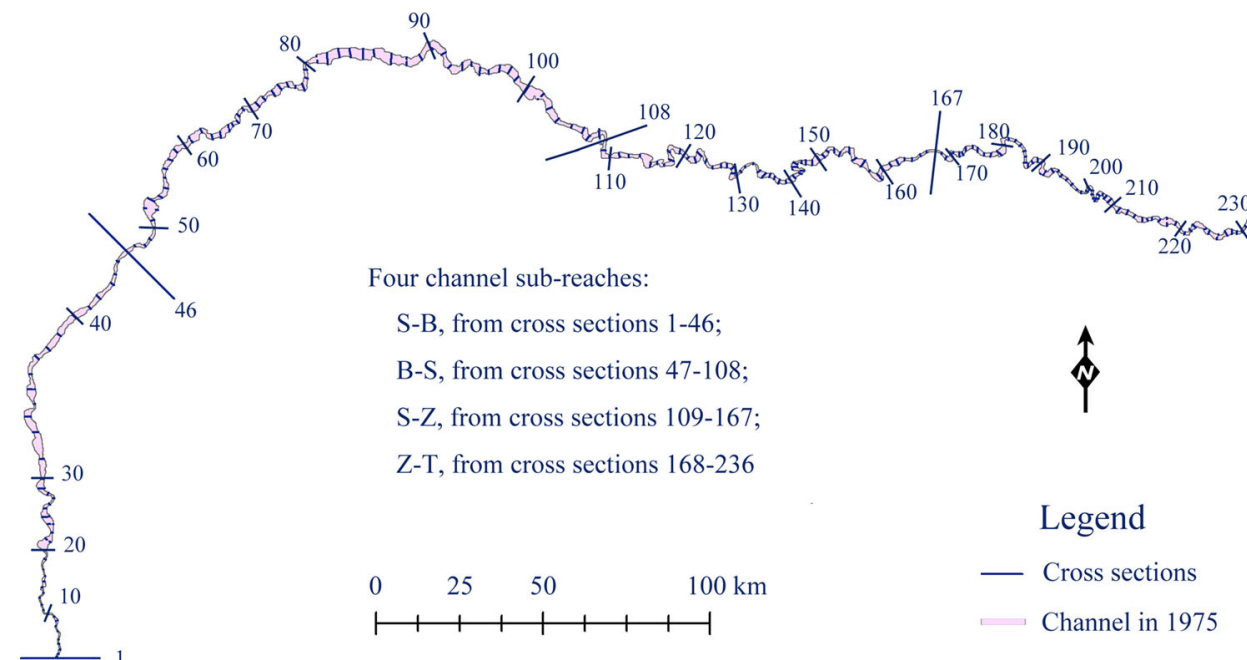

\section{Channel migration rates for the S-B sub-reach}

The channel in the S-B sub-reach has shrunk remarkably, at least since 2000 (Fig. 4a). The channel migration rates presented a significant spatial variation (Fig. 4b). They varied between -34 and $35 \mathrm{~m}$ year $^{-1}$ in the channel from cross-sections 1 to 21 and between -133.4 and $183 \mathrm{~m} \mathrm{year}^{-1}$ in the channel from cross-sections 22 to 46. The maximum migration rate to the right was $56.5,106.2$, $61.8,62.0$, and $182.6 \mathrm{~m} \mathrm{year}^{-1}$ and to the left was 29.4 , 79.6, 133.4, 91.7, and $126.0 \mathrm{~m} \mathrm{year}^{-1}$ in the periods of 1975-1990, 1990-2000, 2000-2006, 2006-2010, and 2010-2011, respectively.

In this river reach, the maximum mean channel migration rate to the left and to the right was in the period of 2010-2011, while the least to the left and to the right was in the periods of 1975-1990 and 2000-2006, respectively (Table 2). In addition, the number of cross-sections migrating to the left bank presented an increase trend in the periods of 1975-1990, 1990-2000, and 2000-2006, while migration to the right bank decreased accordingly over the same periods.

The average migration rate for all the 46 cross-sections was $1.8,10.7,-3.2,-4.0$, and $3.8 \mathrm{~m}$ year $^{-1}$ in the periods of 1975-1990, 1990-2000, 2000-2006, 2006-2010, and 2010-2011, respectively (Table 2). The average migration rates for this channel sub-reach indicated that the channel migrated to the right bank in the first two and the last periods, while to the left bank in the other two periods. Besides, the maximum average migration rate was in the period of 1990-2000 (Fig. 8).

\section{Channel migration rates for the B-S sub-reach}

As shown in Fig. 5a, the channel in the B-S sub-reach has shrunk remarkably and the mid-channel bars have decreased at least since 2000. The channel migration rates exhibited a fluctuant spatial variation (Fig. 5b). The maximum migration rate to the right bank was $183.5,236.7$, 326.6, 348.0, and $382.6 \mathrm{~m} \mathrm{year}^{-1}$, while to the left bank was $145.9,169.9,205.1,278.8$, and $405.0 \mathrm{~m} \mathrm{year}^{-1}$ in the five periods, respectively, and shown an increase trend for both directions.

In this sub-reach, the maximum and least mean channel migration rate to the left and to the right banks was in the periods of 2010-2011 and 1975-1990, respectively (Table 2). The number of cross-sections migrating to the left bank presented an increase trend in the periods of 1975-1990, 1990-2000, and 2000-2006, while migration to the right bank decreased accordingly over the same periods.

The average migration rate for all the 62 cross-sections was $1.1,9.1,13.0,17.2$, and $-1.0 \mathrm{~m} \mathrm{year}^{-1}$ in the five periods, respectively (Table 2). During the former four periods, the average channel migration rate in the sub-reach increased steadily from 1.1 to $17.2 \mathrm{~m} \mathrm{year}^{-1}$, and the ratio is $1: 8.3: 11.8: 15.6$. The overall channel migration for this channel sub-reach was to the right bank. The average migration rate showed an increase trend in all the periods with the exception of 2010-2011 (Fig. 8).

\section{Channel migration rates for the $\mathrm{S}-\mathrm{Z}$ sub-reach}

As shown in Fig. 6a, the channel in the $\mathrm{S}-\mathrm{Z}$ sub-reach has also shrunk substantially at least since 1990 . However, channel shrinkage in this sub-reach occurred earlier than that of the two upriver sub-reaches. The channel migration rates along the $\mathrm{S}-\mathrm{Z}$ sub-reach presented unbalanced spatial fluctuations (Fig. 6b). The maximum migration rate to the right bank was 154.3, 150.2, 197.8, 262.8, and $132.0 \mathrm{~m} \mathrm{year}^{-1}$, while that to the left bank was 112.8 , 
Fig. 4 a Channel planform changes and $\mathbf{b}$ spatial channel migration rate in the channel sub-reach of $S-B$ during different periods
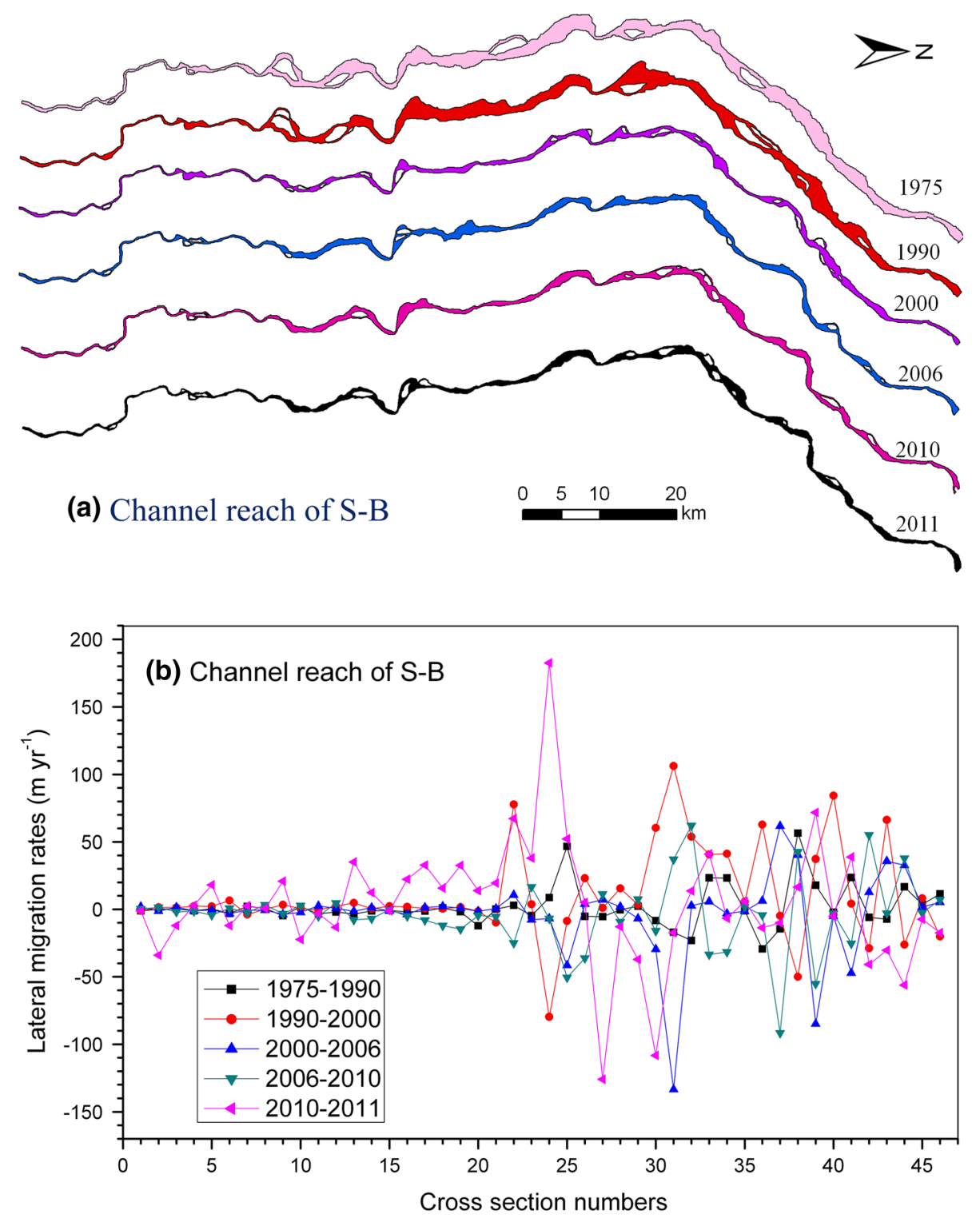

138.6, 418.9, 235.0, and $582.2 \mathrm{~m} \mathrm{year}^{-1}$ in the five periods, respectively.

In this river sub-reach, the maximum mean channel migration rate to the left and right banks was in the periods of 2000-2006 and 2006-2010, respectively, while the least to the left and right banks was in the periods of 1990-2000 and 2000-2006, respectively (Table 2). For all the 59 cross-sections, the average migration rate was 8.6, 15.7, $-35.8,12.4$, and $-13.5 \mathrm{~m}$ year $^{-1}$ during the five periods, respectively. The average migration rates for this channel sub-reach showed that for the whole channel migration, the channel migration was to the right bank in the first two periods, then alternately to the left bank, and finally to the right bank. The maximum average migration rate was in the period of 2000-2006 (Fig. 8).

\section{Channel migration rates for the $\mathrm{Z}-\mathrm{T}$ sub-reach}

As shown in Fig. 7a, the channel in the Z-T sub-reach has also shrunk significantly at least since 1990. The channel migration rates were characterized by apparent spatial differences (Fig. 7b). The maximum migration rate to the right bank was 122.6, 124.8, 161.8, 175.7, and $161.9 \mathrm{~m} \mathrm{year}^{-1}$, while to the left bank was 90.5, 104.7, 182.8, 174.7, and $188.2 \mathrm{~m} \mathrm{year}^{-1}$ in the periods of 1975-1990, 1990-2000, 2000-2006, 2006-2010, and 2010-2011, respectively.

In this river sub-reach, the maximum mean channel migration rate to the left and right banks was all in the periods of 2010-2011, while the least was in the periods of 1975-1990 and 2000-2006, respectively (Table 2). 
Fig. 5 a Channel planform changes and $\mathbf{b}$ spatial channel migration rate in the channel sub-reach of $B-S$ during different periods
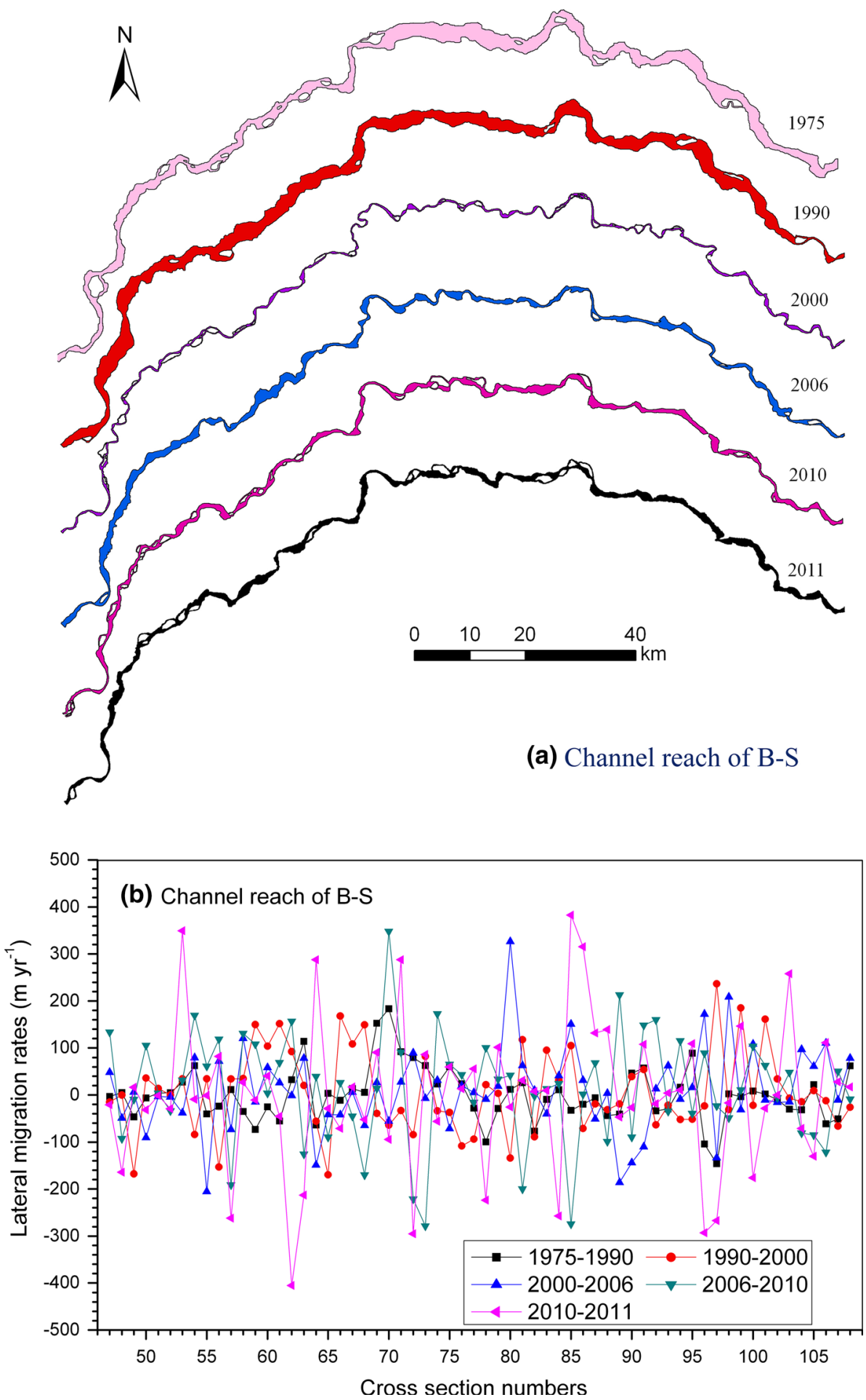

For all the 69 cross-sections, the average migration rate was $14.1,5.0,-4.5,18.6$, and $5.8 \mathrm{~m}_{\text {year }}{ }^{-1}$ during the five periods, respectively. As a whole, the channel migration in this channel sub-reach was to the right bank in all the periods with the exception of 2000-2006 (Fig. 8).

\section{Channel migration rates for the whole river reach}

For the whole river reach, the maximum mean channel migration rate to the left and right banks was all in the periods of 2010-2011, while the least was all in the periods of 1975-1990 (Table 2). For all the 236 cross-sections, the 
Fig. 6 a Channel planform changes and $\mathbf{b}$ spatial channel migration rate in the channel sub-reach of $S-Z$ during different periods
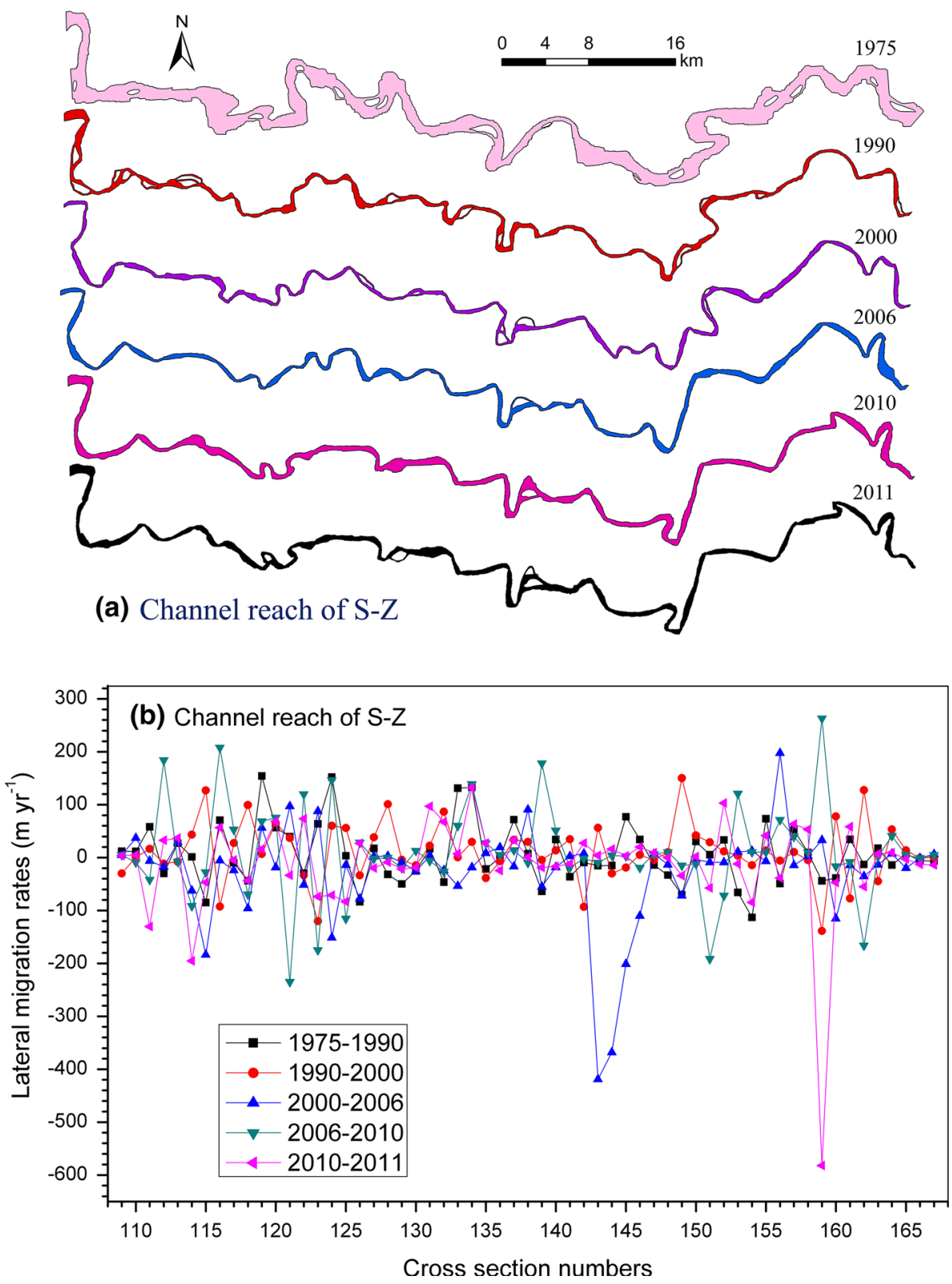

average migration rate was $5.0,7.9,-5.9,8.6$, and $-1.0 \mathrm{~m} \mathrm{year}^{-1}$ in the five periods, respectively, and the maximum average migration rate was in the period of 2006-2010 (Fig. 8).

\section{Discussion}

\section{Comparison of channel migration with other braided rivers}

Similar studies on channel migration or channel bank erosion/accretion of braided rivers have been reported worldwide (e.g., Thorne et al. 1993; Khan and Islam 2003; Richard et al. 2005; Baki and Gan 2012; Wang et al. 2012; Wang and Mei 2016). The channel migration rates show a wide range of variability among diverse braided rivers. In the $45-\mathrm{km}$ Cochiti section of the Rio Grande (NM, USA), for example, Richard et al. (2005) found that the lateral channel migration rates at 284 crosssections during the period 1918-2001 are all less than $30 \mathrm{~m}$ year $^{-1}$ with most even less than $10 \mathrm{~m}_{\text {year }}{ }^{-1}$. As given in Table 2, the mean channel migration rates in the Inner Mongolian reach of the upper Yellow River are closer to those values. However, most migration rates to the left and right banks during certain time periods are significantly greater than those values. This suggests that the channel of the Inner Mongolian reach is more vulnerable to lateral migration than the Cochiti section of the Rio Grande. 
Fig. 7 a Channel planform changes and $\mathbf{b}$ spatial channel migration rate in the channel sub-reach of $Z-T$ during different periods
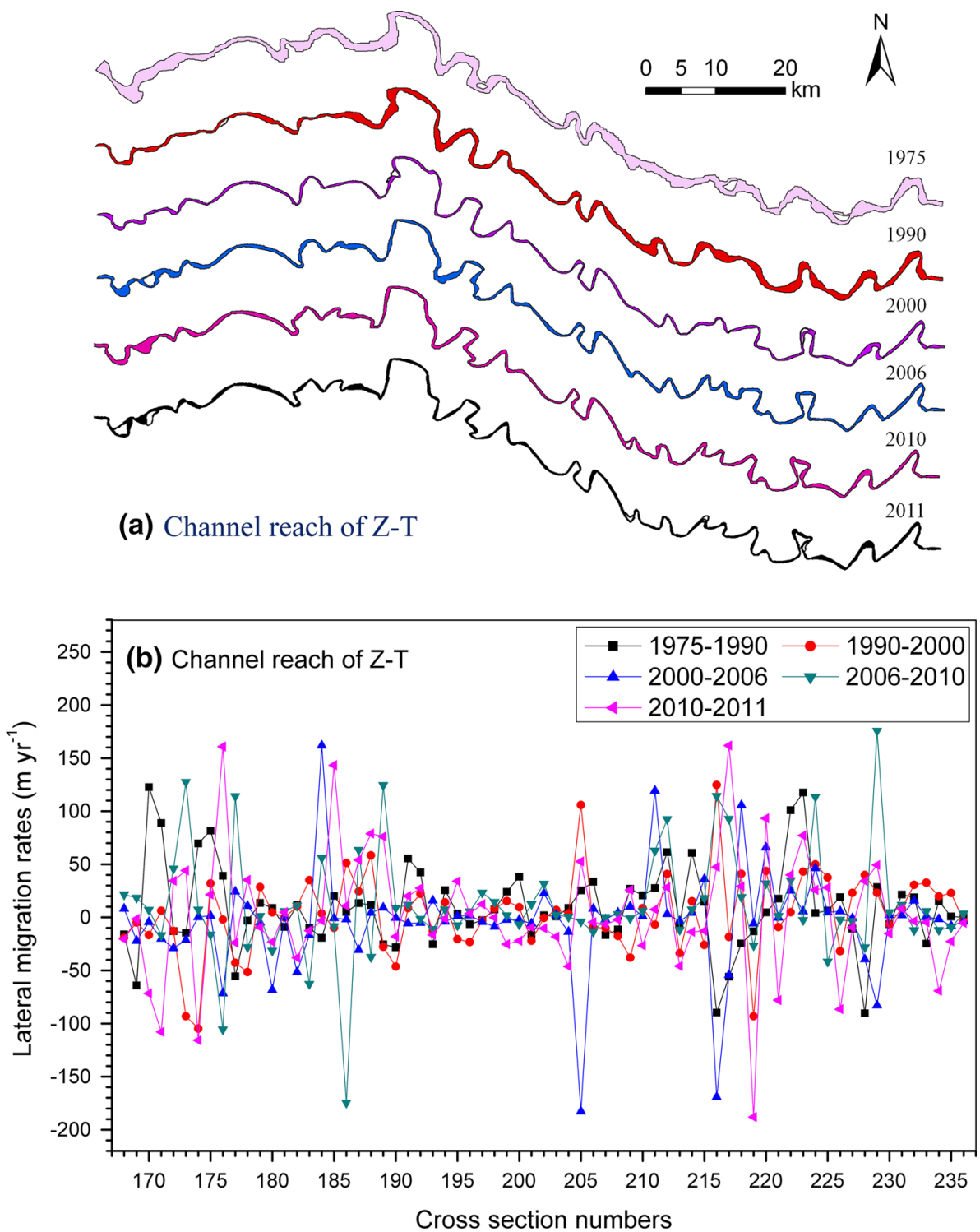

Baki and Gan (2012) indicated that the mean shortterm erosion rate on the left and right banks of the Jamuna River is 227 and $187 \mathrm{~m}$ year $^{-1}$, respectively, while the maximum erosion rate is about $364 \mathrm{~m}_{\text {year }}{ }^{-1}$ to the left bank and $460 \mathrm{~m} \mathrm{year}^{-1}$ to the right bank. Therefore, this represents a net accretion of about $40 \mathrm{~m}$ to both the left and right banks. Clearly, those migration rates to both the left and right banks are greater than that of the Inner Mongolian reach over different time periods (Table 2). In addition, the mean long-term erosion rates to the left and right banks of the Jamuna River are 90 and $75 \mathrm{~m}_{\text {year }}{ }^{-1}$, respectively, while the mean long-term accretion rates to both banks over 30 years are 104 and $50 \mathrm{~m} \mathrm{year}^{-1}$, respectively (Baki and Gan 2012). The mean long-term migration rates to both banks of the Jamuna River are also greater than that of the Inner
Mongolian reach over the 36 years from 1975 to 2011 (Table 2). It can be concluded that the channel lateral movability of the Inner Mongolian reach of the upper Yellow River is lower than that of the Jamuna River.

It is worth to point out that the long-term channel migration rate or bank erosion/accretion rate is considerably lower than the short-term for both the Inner Mongolian reach of the upper Yellow River and the Jamuna River. Similar phenomenon has also been reported by Wang et al. (2012) in their study on the braided Yinchuan reach in the upper Yellow River. As Wang et al. (2012) have suggested the lower long-term migration rates of channel or bank shift were influenced inevitably by the to-and-fro shifts of banks, while the short-term migration rates were more controlled by bank shift in one direction. 
Table 2 Mean channel migration rate in different channel sub-reaches and in the total channel reach during the five different periods

\begin{tabular}{|c|c|c|c|c|c|c|c|c|c|c|c|}
\hline \multirow[t]{2}{*}{ Channel reach } & \multirow[t]{2}{*}{ Direction } & \multicolumn{2}{|c|}{ 1975-1990 } & \multicolumn{2}{|c|}{ 1990-2000 } & \multicolumn{2}{|c|}{ 2000-2006 } & \multicolumn{2}{|c|}{ 2006-2010 } & \multicolumn{2}{|c|}{ 2010-2011 } \\
\hline & & $N$ & Rate & $N$ & Rate & $N$ & Rate & $N$ & Rate & $N$ & Rate \\
\hline \multirow[t]{2}{*}{ S-B } & Leftward & 26 & -6.3 & 12 & -19.5 & 23 & -16.9 & 30 & -15.9 & 22 & -26.7 \\
\hline & Rightward & 20 & 12.2 & 34 & 21.4 & 23 & 10.5 & 16 & 18.3 & 24 & 31.7 \\
\hline Mean & & 46 & 1.8 & 46 & 10.7 & 46 & -3.2 & 46 & -4.0 & 46 & 3.8 \\
\hline \multirow[t]{2}{*}{ B-S } & Leftward & 31 & -41.0 & 32 & -59.1 & 29 & -57.7 & 25 & -95.4 & 31 & -108.8 \\
\hline & Rightward & 31 & 42.6 & 30 & 77.0 & 33 & 68.8 & 37 & 85.9 & 31 & 107.3 \\
\hline Mean & & 62 & 1.1 & 62 & 9.1 & 62 & 13.0 & 62 & 17.2 & 62 & -1.0 \\
\hline \multirow[t]{2}{*}{$\mathrm{S}-\mathrm{Z}$} & Leftward & 28 & -37.2 & 23 & -35.4 & 37 & -63.6 & 27 & -50.7 & 28 & -61.5 \\
\hline & Rightward & 31 & 46.4 & 36 & 42.6 & 22 & 32.0 & 32 & 60.6 & 31 & 35.6 \\
\hline Mean & & 59 & 8.6 & 59 & 15.7 & 59 & -35.8 & 59 & 12.4 & 59 & -13.5 \\
\hline \multirow[t]{2}{*}{ Z-T } & Leftward & 26 & -25.8 & 32 & -25.9 & 36 & -26.4 & 26 & -26.1 & 38 & -31.7 \\
\hline & Rightward & 43 & 30.7 & 37 & 28.6 & 33 & 22.5 & 43 & 35.7 & 31 & 47.4 \\
\hline Mean & & 69 & 14.1 & 69 & 5.0 & 69 & -4.5 & 69 & 18.6 & 69 & 5.8 \\
\hline \multirow[t]{2}{*}{ Total } & Leftward & 111 & -28.3 & 99 & -38.1 & 125 & -42.9 & 108 & -45.5 & 119 & -57.9 \\
\hline & Rightward & 125 & 34.6 & 137 & 41.1 & 111 & 35.7 & 128 & 54.2 & 117 & 56.9 \\
\hline Mean & & 236 & 5.0 & 236 & 7.9 & 236 & -5.9 & 236 & 8.6 & 236 & -1.0 \\
\hline
\end{tabular}

S-B, Shizuishan-Bayangaole with cross-sections from 1 to 46; B-S, Bayangaole-Sanhuhekou with crosssections from 47 to 108; S-Z, Sanhuhekou-Zhaojunfen with cross-sections from 109 to 167; Z-T, Zhaojunfen-Toudaoguai with cross-sections from 168 to 236. $N$ is number of the cross-sections. Rate represents mean channel migration rate

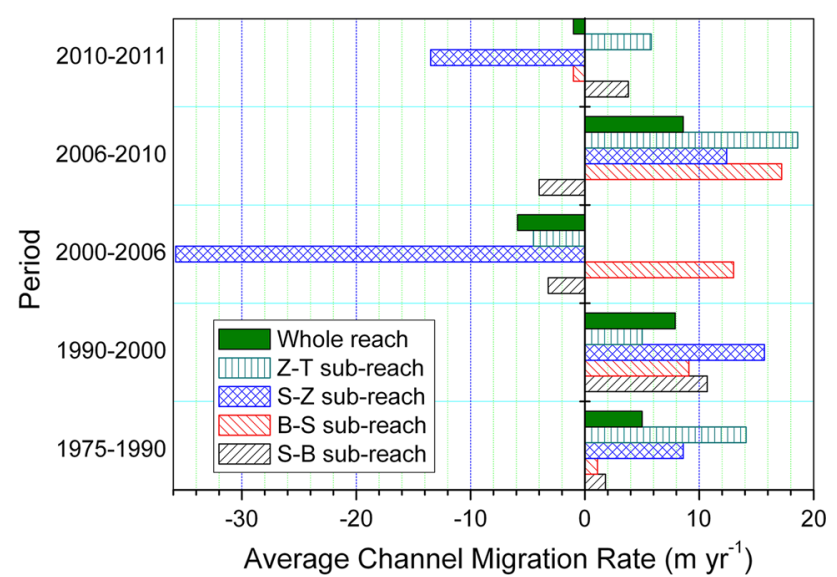

Fig. 8 Average channel migration rate in the four sub-reaches and in the whole river reach during different periods

\section{Temporal variation and the influences of runoff and sediment changes}

Temporal variation of the channel migration rates in the study river reach showed great differences. The maximum channel migration rate to the right bank for the whole river reach was 183.5, 236.7, 326.6, 348.0, and $382.6 \mathrm{~m}_{\text {year }}{ }^{-1}$, while to the left bank was 145.9, 169.9, 418.9, 278.7, and $582.2 \mathrm{~m} \mathrm{year}^{-1}$ in the periods of 1975-1990, 1990-2000, 2000-2006, 2006-2010, and 2010-2011, respectively. Furthermore, the average channel migration rate for the whole river reach was 5.0, 7.9, $-5.9,8.6$, and -1.0 year $^{-1}$ in the five periods. Obviously, the maximum migration rate increased evidently after 2000, while the average migration rate was high in the period from 1990 to 2010. Major influencing factors for channel migration include mainly the channel boundary condition that denotes the ability of channel bank resistance to erosion and water and sediment input which reflects the stream power. Given that the channel boundary condition could not change remarkably over the past decades, it is expected that variations of the water and sediment input are the major driving factor.

The annual runoff and suspended sediment load (SSL) in the study river reach fluctuated simultaneously before the operation of Liujiaxia and Qingtongxia dams in 1968 (Fig. 9a). In the period from 1968 to 1974, while both runoff and suspended sediment load decreased sharply, the magnitude of SSL reduction was greater than that of the runoff due largely to the water storage and sediment detention by the two dams. As a result of altered seasonal storage and storage caused by reservoir operation, the annual runoff and SSL in the Inner Mongolian reach during the period 1975-1985 were greater than those in the period of 1968-1974. Since 1986 when the Longyangxia dam was constructed, both the mean annual runoff and SSL have decreased rapidly to the minimum levels. Further, the change in reservoir operation mode could change the magnitude of runoff and SSL transport in the flooding season, thereby changing the sediment concentration (SC). For example, the $\mathrm{SC}$ in the flooding season has decreased remarkably since 2000 (Fig. 9b), which could enhance the erosion ability of river flow. As a result, the maximum channel migration rate in the river reach showed an increase trend. The 


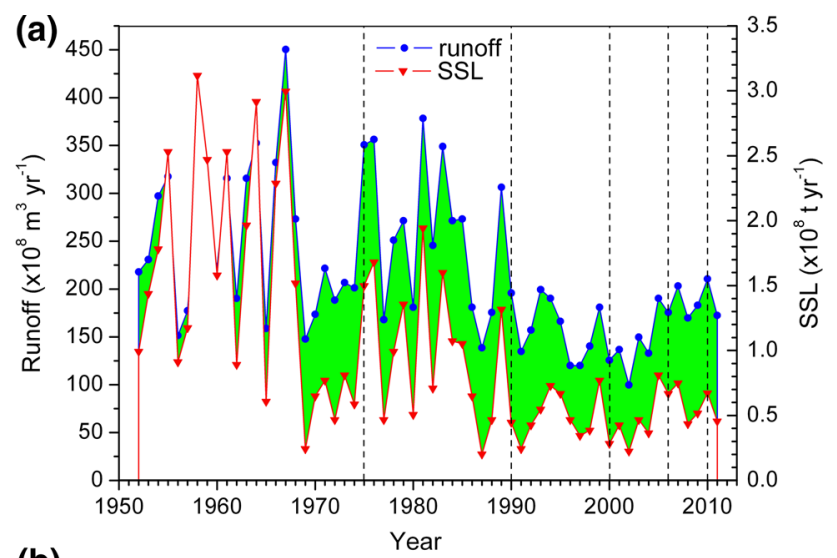

(b)

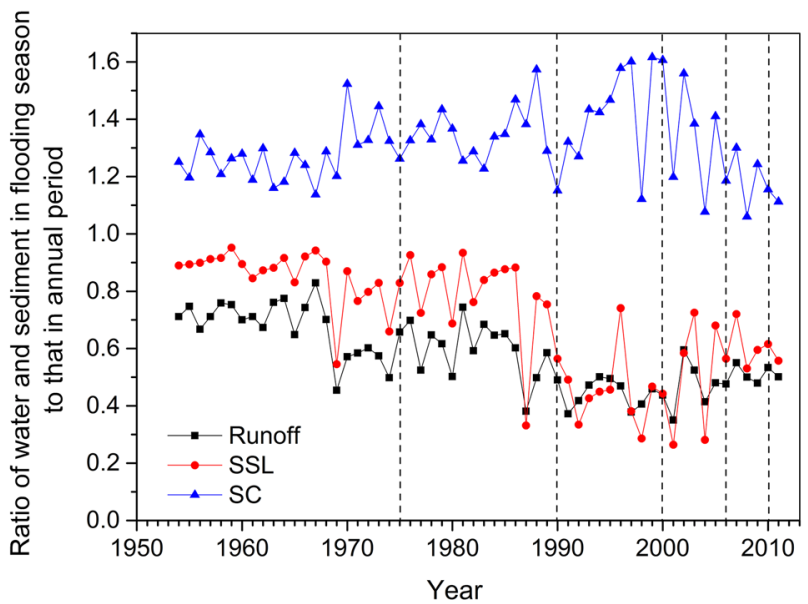

Fig. 9 a Annual runoff and suspended sediment load (SSL) at the Sanhuhekou gauging station; b ratios of runoff, SSL and sediment concentration (SC) in flooding season (from May to October) to that in annual period, respectively, at the Sanhuhekou gauging station

average channel migration rates for both directions ranged from 5.0 to $8.6 \mathrm{~m} \mathrm{year}^{-1}$ over the whole period, except the period of 2010-2011. This suggests that the average channel migration rate for the river reach did not decrease synchronously with the significant decreases in runoff and SSL (Fig. 9a). In comparison, the average channel migration rate in the period from 2000 to 2006, when both runoff and SSL were very low, was even greater than that in the period from 1975 to 1990 when the runoff and SSL were very high. It can be concluded that the average channel migration rate was rather influenced by SC than by runoff and SSL.

\section{Spatial variation and the impacts of channel boundary materials}

Channel migration rate can reflect the lateral mobility of a channel (Wang et al. 2014) and even the sediment compositions of channel banks. As mentioned above, the temporal variation of the channel migration rate in a short channel reach is mostly influenced by changing water and sediment dynamics, especially the SC. However, the spatial variation of the channel migration rate could be affected by various channel boundary conditions. A number of different channel patterns are developed in the Inner Mongolian Reach (Wang and Fan 2010), which would have been the results of different conditions of the channel boundary.

The greatest average channel migration rate was always observed in the $\mathrm{S}-\mathrm{Z}$ or $\mathrm{Z}-\mathrm{T}$ reaches (Fig. 8). As mentioned above, both reaches belong to the meandering channel pattern. The channel banks are composed of double-layer sediment structure, with the lower layer being thick silt while the upper layer thin clay. The silt layer is vulnerable to lateral erosion by river flow, while the impending part of the clay layer would collapse easily. As a consequence, the channel forms a series of bends via lateral erosion and spatially shows a meandering pattern. With the lateral and longitudinal shifts of the bends, the channel reaches exhibit the greatest average lateral migration rate among the different channel pattern reaches studied here.

The B-S reach shows a braided channel pattern with broad channel bed and a large number of mid-channel bars. Most part of the channel reach has a lower sinuosity (Table 3), higher channel gradient than that of the meandering reach (Wang et al. 2012). Moreover, its banks are mainly composed of muddy silt materials. These characteristics lead the channel reach to consume its stream power by scouring the channel bed and altering the location of the mid-channel bars, rather than laterally eroding banks. Consequently, the average channel lateral migration rate in this river reach is lower than that in the meandering reach.

As mentioned earlier, the upper section of the S-B reach is characterized by outcrop of bedrock. Although the mean channel migration rate is very small in this bedrock section due to its strong resistance to erosion, the average channel migration rate for the whole $\mathrm{S}-\mathrm{B}$ reach is slightly greater than that for the braided reach (i.e., B-S reach) in the period from 1975 to 1990 . A major reason is that most of the channel reach is located in the margin of the Wulanbuhe Desert (Fig. 1). The desert sand composed mainly of silt is lack of cohesiveness and is thus susceptible to lateral erosion. Furthermore, the channel gradient is almost twice that for the braided channel reach. This leads the river in the S-B reach to have higher power than that for the braided channel reach. These features result in the relatively higher channel migration rate. However, the channel average migration rate for the braided channel reach is obviously greater than that for the straight channel reach during the period 1990-2010.

\section{Conclusions}

Based on satellite images in 6 years $(1975,1990,2000$, 2006, 2010, and 2011) and 236 delineated cross-sections from the images, the channel lateral migration rates at the 
Table 3 Channel sinuosity index in the different years and its change in the different periods for the four sub-reaches

\begin{tabular}{lcccc}
\hline Year or period & Shizuishan-Bayangaole & Bayangaole-Sanhuhekou & Sanhuhekou-Zhaojunfen & Zhaojunfen-Toudaoguai \\
\hline 1975 & 1.212 & 1.282 & 1.53 & 1.312 \\
1990 & 1.216 & 1.223 & 1.363 & 1.447 \\
2000 & 1.219 & 1.404 & 1.465 & 1.648 \\
2006 & 1.203 & 1.351 & 1.430 & 1.690 \\
2010 & 1.202 & 1.283 & 1.415 & 1.701 \\
2011 & 1.247 & 1.348 & 1.505 & 1.819 \\
$1975-1990$ & 0.004 & -0.059 & -0.167 & 0.135 \\
$1990-2000$ & 0.003 & 0.181 & 0.102 & 0.201 \\
$2000-2006$ & -0.016 & -0.053 & -0.035 & 0.042 \\
$2006-2010$ & -0.001 & -0.068 & -0.015 & 0.011 \\
$2010-2011$ & 0.045 & 0.065 & 0.09 & 0.118 \\
$1975-2011$ & 0.035 & 0.066 & -0.025 & 0.507 \\
\hline
\end{tabular}

cross-sections and average migration rates in four subreaches in five periods (1975-1990, 1990-2000, 2000-2006, 2006-2010, and 2010-2011) were calculated.

1. The spatial variation of channel migration rates in the four sub-reaches ( $\mathrm{S}-\mathrm{B}, \mathrm{B}-\mathrm{S}, \mathrm{S}-\mathrm{Z}$, and $\mathrm{Z}-\mathrm{T}$ ) shows different trends in different periods. Small migration rates were observed at the beginning section of the $\mathrm{S}$ $\mathrm{B}$ sub-reach in all the periods, because this section is characterized by bedrock channel at some locations. Alternate channel migrations to the left and right banks are the common characteristics for all the sub-reaches. The maximum average channel migration rates for all the sub-reaches are in the period from 2000 to 2010, which was mainly caused by decreasing sediment concentration in river flow induced by human activities, such as farmland irrigation and water withdrawal for domestic and industrial consumptions.

2. The maximum channel migration rate is in the $B-S$ sub-reach which exhibits a braided channel pattern, but the average migration rate in this sub-reach is not the highest among the channel reaches in all the periods. This denotes that, in the braided channel reach, severe lateral erosion could occur in specific sections with a relative narrow and deep water flow or relative high channel sinuosity.

3. The maximum channel average migration rate to the left bank is in the $\mathrm{S}-\mathrm{Z}$ sub-reach and to the right bank is in the Z-T sub-reach, both of which present a meandering channel. This indicates that the maximum lateral migration rate is induced by sediment compositions of the channel banks of the meandering channel.

4. Considering the greatest average lateral migration rate to the left bank, the $\mathrm{S}-\mathrm{Z}$ sub-reach is a key river reach to be protected from channel lateral migration because a large population and wide farmland are located on its left floodplain.

Acknowledgments We would like to thank the U.S. Geological Survey for the satellite imageries used in this study and the Yellow River Water Conservancy Committee for the access permission to the hydrological gauging data. This study is financially supported by the projects of the National Science Foundation of China (41571005, 41271027) and the National Basic Research Program of China (2011CB403305).

\section{References}

Alam JB, Uddin M, Ahmed UJ, Cacovean H, Rahman HM, Banik BK, Yesmin N (2007) Study of morphological change of river old Brahmaputra and its social impacts by remote sensing. Geographia Technica (issue no. 4, no. 2), 1-11

Baki ABM, Gan TY (2012) Riverbank migration and island dynamics of the braided Jamuna River of the Ganges Brahmaputra basin using multi-temporal Landsat images. Quatern Int 263:146-161

Belletti B, Dufour S, Piégay H (2015) What is the relative effect of space and time to explain the braided river width and island patterns at a regional scale? River Res Appl 31(1):1-15

Brandt SA (2000) Classification of geomorphological effects downstream of dams. Catena 40:375-401

Church M (1995) Geomorphic response to river flow regulation: case studies and time-scales. Regul Rivers Res Manag 11:3-12

Fotherby LM (2009) Valley confinement as a factor of braided river pattern for the Platte River. Geomorphology 103:562-576

Gurnell AM (1997) Channel change on the River Dee meanders, 1946-1992, from the analysis of air photographs. Regul Rivers Res Manag 12:13-26

Hossain MA, Gan TY, Baki ABM (2013) Assessing morphological changes of the Ganges River using satellite images. Quat Int 304:142-155

Hou S, Chang W, Wang P, Chu W (2007) Characteristics and cause of formation of channel atrophy at Inner Mongolia reach of the Yellow River. Yellow River 29:25-29 (in Chinese)

Khan NI, Islam A (2003) Quantification of erosion patterns in the Brahmaputra-Jamuna River using geographical information system and remote sensing techniques. Hydrol Process 17:959-966 
Kummu M, Lu XX, Rasphone A, Sarkkula J, Koponen J (2008) Riverbank changes along the Mekong River: remote sensing detection in the Vientiane-Nong Khai area. Quatern Int 186:100-112

Moshe LB, Haviv I, Enzel Y, Zilberman E, Matmon A (2008) Incision of alluvial channels in response to a continuous base level fall: field characterization, modeling, and validation along the Dead Sea. Geomorphology 93(3-4):524-536

Nicoll TJ, Hickin EJ (2010) Planform geometry and channel migration of confined meandering rivers on the Canadian prairies. Geomorphology 116:37-47

Petts GE (1979) Complex response of river channel morphology subsequent to reservoir construction. Prog Phys Geogr 3:329-362

Petts GE (1984) Sedimentation within a regulated river. Earth Surf Proc Land 9:125-134

Petts GE (1995) Changing river channels: the geographical tradition. In: Gurnell A, Petts G (eds) Changing river channels. Wiley, New York, pp 1-23

Ran L, Wang S, Fan X (2010) Channel change at Toudaoguai Station and its responses to the operation of upstream reservoirs in the upper Yellow River. J Geogr Sci 20(2):231-247

Ran L, Wang S, Lu XX (2012) Hydraulic geometry change of a large river: a case study of the upper Yellow River. Environ Earth Sci 66:1247-1257

Richard GA, Julien PY, Baird DC (2005) Statistical analysis of lateral migration of the Rio Grande, New Mexico. Geomorphology $71: 139-155$

Shen G, Zhang Y, Hou S (2007) Impact of water and sediment regulation by reservoirs in the upper Yellow River on Inner Mongolia reaches. J Sedim Res 1:67-75 (in Chinese)

Takagi T, Oguchi T, Matsumoto J, Grossman MJ, Sarker MH, Matin MA (2007) Channel braiding and stability of the Brahmaputra River, Bangladesh, since 1967: GIS and remote sensing analyses. Geomorphology 85(3):294-305

Thorne CR, Russell APG, Alam MK (1993) Planform pattern and channel evolution of the Brahmaputra River Bangladesh. Geol Soc London Spec Publ 75:257-276
Twidale CR (2004) River patterns and their meaning. Earth-Sci Rev 67:159-218

Wang S, Fan X (2010) Flood processes and channel responses in typical years of the different channel patterns in Neimenggu reaches of the upper Yellow River. Prog Geogr 29(4):501-506 (in Chinese)

Wang S, Li Y (2011) Channel variations of the different channel pattern reaches in the lower Yellow River from 1950 to 1999. Quatern Int 244:238-247

Wang S, Mei Y (2016) Lateral erosion/accretion area and shrinkage rate of the Linhe reach braided channel of the Yellow River between 1977 and 2014. Journal of Geographical Sciences (in press)

Wang S, Yan Y, Li Y (2012) Spatial and temporal variations of suspended sediment deposition in the alluvial reach of the upper Yellow River from 1952 to 2007. Catena 92:30-37

Wang S, Li L, Cheng W (2014) Variations of bank shift rates along the Yinchuan Plain reach of the Yellow River and their influence factors. J Geogr Sci 24(4):703-716

Winterbottom S (2000) Medium and short-term channel planform changes of the Rivers Tay and Tummel, Scotland. Geomorphology 34:195-208

Yao Z, Ta W, Jia X, Xiao J (2011) Bank erosion and accretion along the Ningxia-Inner Mongolia reaches of the Yellow River from 1958 to 2008. Geomorphology 127(1-2):99-106

Yao Z, Xiao J, Ta W, Jia X (2013) Planform channel dynamics along the Ningxia-Inner Mongolia reaches of the Yellow River from 1958 to 2008: analysis using Landsat images and topographic maps. Environ Earth Sci 70:97-106

Yellow River Conservancy Commission (1989) Yellow River Valley Atlas. Chinese Map Press, Beijing, 276-278 (in Chinese)

Yellow River Water Conservancy Committee (1952-2011) Annual report of yellow water and sediment (interior report, in Chinese)

Zahar Y, Ghorbel A, Albergel Jean (2008) Impacts of large dams on downstream flow conditions of rivers: aggradation and reduction of the Medjerda channel capacity downstream of the Sidi Salem dam (Tunisia). J Hydrol 351(3-4):318-330 